Strategi Guru PAI... | 43

\title{
STRATEGI GURU PAI DALAM MENGEMBANGKAN KECERDASAN SPIRITUAL SISWA SECARA DARING
}

\author{
Komariah 1) * \\ Hamdanah 2) \\ Surawan ${ }^{3)}$ \\ 1, 2, 3 Program Studi Pendidikan Agama Islam \\ Institut Agama Islam Negeri (IAIN) Palangka Raya \\ *E-mail: Komariah259@gmail.com
}

\begin{abstract}
This study aims to determine the strategy of Islamic Education teachers in developing students' spiritual intelligence online at SMAN 1 Pantai Lunci. This type of research is qualitative using descriptive qualitative methods. The subjects of this study were PAI teachers while the informants in this study were students, BK teachers and parents of students. Data collection techniques using observation, interviews, documentation. The data validation technique used source triangulation and technique triangulation. The data analysis technique was carried out by collecting data, reducing data, presenting data and drawing conclusions. The results of this study indicate that the PAI teacher strategy in developing students' spiritual intelligence online at SMAN 1 Pantai Lunci is an independent learning strategy by going through several stages, namely determining learning objectives, delivering learning materials and giving independent assignments in the form of summarizing the Angel Always with Me material which contains the value of faith and reading the Qur'an which contains the value of worship, then independent activities and the last stage is to do an evaluation.
\end{abstract}

Keywords: Spiritual Intelligence, PAI Learning, Teacher Strategy

\begin{abstract}
Abstrak
Penelitian ini bertujuan untuk mengetahui strategi guru PAI dalam mengembangkan kecerdasan spiritual siswa secara daring di SMAN 1 Pantai Lunci. Jenis penelitian ini adalah kualitatif dengan menggunakan metode kualitatif deskriptif. Subjek penelitian ini adalah guru PAI sedangkan informan dalam penelitian ini adalah siswa, guru BK dan orang tua siswa. Teknik pengumpulan data menggunakan observasi, wawancara, dokumentasi. Teknik pengabsahan data menggunakan triangulasi sumber dan triangulasi teknik. Teknik analisis data dilakukan dengan pengumpulanndata, reduksi data, penyajian data dan menarik kesimpulan. Hasil penelitian ini menunjukkan bahwa strategi guru PAI dalam mengembangkan kecerdasan spiritual siswa secara daring di SMAN 1 Pantai Lunci adalah strategi pembelajaran mandiri dengan melalui beberapa tahapan yaitu menentukan tujuan pembelajaran, menyampaikan materi pembelajaran dan pemberian tugas mandiri berupa merangkum materi Malaikat Selalu Bersamaku yang di dalamnya mengandung nilaia akidah dan membaca alQur'an yang didalamnya mengandung nilai ibadah, kemudian kegiatan mandiri dan tahapan yang terakhir yaitu dengan melakukan evaluasi.
\end{abstract}

Kata Kunci: Kecerdasan Spiritual, Pembelajaran PAI, Strategi Guru 
44 | Komariah, Hamdanah, \& Surawan

\section{PENDAHULUAN}

Sekolah merupakan salah satu kebutuhan pokok manusia yang harus dipenuhi untuk membantu kehidupannya di kemudian hari. Pendidikan berdasarkan UU No. 20 Tahun 2003 tentang Sistem Pendidikan Nasional dalam BAB 1 Pasal 1 ayat 1 menjelaskan bahwa:

"Pendidikan adalah usaha sadar dan terencana untuk mewujudkan suasana belajar dan proses pembelajaran agar siswa secara aktif mengembangkan potensi dirinya untuk memiliki kekuatan spiritual keagamaan, pengendalian diri, kepribadian, kecerdasan, akhlak mulia, serta keterampilan yang diperlukan dirinya, masyarakat, bangsa dan negara".

Senada dengan hal di atas UU No. 20 Tahun 2003 tentang Sistem Pendidikan Nasional dalam BAB 2 pasal 3 dijelaskan bahwa:

"Pendidikan berfungsi untuk mengembangkan kemampuan dan bentuk watak serta peradaban bangsa yang martabatnya dalam rangka mencerdaskan kehidupan bangsa, bertujuan untuk berkembangnya potensi peserta didik menjadi manusia yang beriman dan bertakwa kepada Tuhan yang maha esa, berakhlak mulia, sehat berilmu, cakap, kreatif, mandiri dan menjadi warga negara yang demokratis serta bertanggung jawab".

Bersumber pada UU di atas tujuan pembelajaran bukan cuma mencerdaskan kehidupan bangsa tapi jua meningkatkan kemampuan siswa agar menjadi manusia yang beriman serta bertakwa kepada Tuhan YME serta mempunyai kekuatan spiritual keagamaan. Keberhasilan dalam mencapai tujuan tersebut dalam lingkup pendidikan sekolah dipengaruhi oleh beberapa faktor salah satunya adalah guru.

Pendidik adalah ahli yang memiliki peran penting dalam pembelajaran untuk mencapai tujuan sekolah umum. Untuk keadaan ini, khususnya guru PAI selain bertugas untuk mencerdaskan secara intelektual, guru PAI juga bertugas untuk mencerdaskan secara spiritual.

Namun kenyataannya, tidak semua guru Pendidikan Agama Islam berperan seperti itu. Terkadang, dalam proses pembelajaran guru Pendidikan Agama Islam hanya mengedepankanmkecerdasan intelektual tanpa mementingkan kecerdasan spiritual. Bahkan Pendidikan Agama Islam yang seharusnya menjadi media utama dalam pengembangan kecerdasan spiritual kebanyakan lebih mengacu kepada kecerdasan intelektual saja. Sementara itu, di era globalisasi saat ini sangat minim 
siswa yang menerapkan nilai-nilai spiritual dalam kehidupan sehari-hari seperti melakukan perbuatan menyontek, penyalah gunaan narkoba dan perbuatan lainnya yang dapat menghilangkan nilai-nilai spiritual dalam kehidupan.

Selanjutnya, upaya menumbuhkan kecerdasan spiritual pada siswa merupakan salah satu cara yang harus diterapkan oleh setiap komponen pembinaan saat ini, khususnya oleh para pendidik Pendidikan Agama Islam. Pendidik Pendidikan Agama Islam memiliki peran penting dalam mengembangkan kecerdasan spiritual, di samping lingkungan keluarga yang merupakan lingkungan utama bagi pengembangan kecerdasan spiritual.

Sedangkan itu, di tengah pandemi COVID- 19 yang berlangsung di bermacam negeri termasuk Indonesia, berakibat pada bidang kehidupan, salah satunya di bidang pembelajaran. Sehubungan dengan hal tersebut, bertepatan pada 24 Maret 2020 Kemendikbud RI mengeluarkan surat edaran No 4 Tahun 2020 tentang penerapan kebijakan pembelajaran dalam masa darurat penyebaran COVID- 19, ialah pergantian belajar tatap muka di sekolah jadi belajar dari rumah melalui pembelajaran daring/jarak jauh. Mengacu kepada surat edaran tersebut, sekolah-sekolah di wilayah yang terkena dampak COVID-19 akhirnya mengalihkan interaksi pembelajaran yang semula dilakukan secara tatap muka di sekolah menjadi pembelajaran secara daring. Pelaksanaan pembelajaran secara daring diharapkan dapat mencegah penyebaran dan penularan COVID-19 di satuan pendidikan. Aplikasi google classroom, rumah belajar, video converence, telepo atau live chat, zoom, whatsapp group adalah teknologi digital yang dapat dimanfaatkan dalam pembelajaran daring (Dewi, 2020, 58).

Salah satu sekolah yang melaksanakan pembelajaran secara daring adalah SMAN 1 Pantai Lunci sehingga pengembangan kecerdasan spiritual yang dilakukan oleh guru PAI juga dilaksanakan secara daring. Berdasarkan hasil wawancara dengan guru PAI dan siswa SMAN 1 Pantai Lunci sebagai studi pendahuluan pengembangan kecerdasan spiritual yang dilakukan oleh guru PAI secara daring ini menggunakan google classroom. Strategi guru PAI dalam mengembangkan kecerdasan spiritual siswa secara daring ini melalui strategi pembelajaran mandiri dan strategi pembelajaran afektif yang di dalamnya menghubungkan tentang nilai-nilai spiritual yang ada. Namun, pengembangan kecerdasan spiritual yang dilakukan oleh guru PAI di SMAN 1 Pantai Lunci belum sebagaimana yang diharapkan oleh guru Pendidikan Agama Islam itu sendiri, hal ini ditandai dengan adanya siswa yang masih belum mempraktikkan secara 
nyata makna dan nilai-nilai spiritual yang terkandung dalam pembelajaran Pendidikan Agama Islam yakni masih ada siswa yang belum memahami tujuan hidupnya (memiliki visi) sehingga masih banyak yang masih melalaikan ajaran-ajaran-Nya.

Oleh karena itu guru Pendidikan Agama Islam di SMAN 1 Pantai Lunci harus memberikan kontribusinya kepada siswa dalam hal mengembangkan kecerdasan spiritualnya melalui strategi pembelajaran yang dilakukannya sehingga siswa mampu menerapkannya dalam kehidupan sehari-hari guna memiliki kecerdasan baik cerdas secara akidah, cerdas secara ihsan, cerdas secara ibadah dan cerdas secara akhlak.

Berdasarkan pemaparan di atas, maka peneliti berkeinginan untuk melakukan penelitian yang berjudul "Strategi Guru PAI dalam Mengembangkan Kecerdasan Spiritual Siswa Secara Daring di SMAN 1 Pantai Lunci".

\section{METODE PENELITIAN}

\section{Jenis Penelitian}

Penelitian ini menggunakan jenis penelitian kualitatif dengan menggunakan metode penelitian kualitatif deskriptif denga nmenjabarkan atau memaparkan dengan konkret kondisi objek yang diteliti.

\section{Waktu dan Tempat Penelitian}

Penelitian ini dilaksanakan selama 2 bulan terhitung mulai bulan Februari sampai bulan April di SMAN 1 Pantai Lunci.

\section{Target/Subjek Penelitian}

Subjek dalam penelitian ini adalah satu orang guru Pendidikan Agama Islam sedangkan informan dalam penelitian ini adalah siswa, guru BK dan orang tua siswa.

\section{Data, Instrumen, dan Teknik Pengumpulan Data}

Penggalian data dilakukan melalui observasi terhadap strategi guru PAI dalam mengembangkan kecerdasan spiritual siswa secara daring, juga melalui wawancara kepada guru PAI sebagai subjek dan siswa, orang tua siswa serta guru BK sebagai informan dalam penelitian ini. Kemudian melalui dokumen di antaranya dokumen RPP guru dan buku ajar.

Instrumen yang digunakan sebagai pendukung data dalam penelitian ini adalah pedoman observasi, wawancara, pedoman dokumentasi dan alat dokumentasi berupa alat rekam audio/ video. Teknik pengumpulan data yang digunakan yaitu wawancara, 
observasi dan dokumentasi. Untuk wawancara, peneliti menggunakan wawancara semi terstruktur, dimana peneliti menyediakan beberapa set pedoman wawancara untuk memperoleh data sesuai dengan pernyataan penelitian yaitu strategi guru PAI dalam meningkatkan kecerdasan spiritual. Sedangkan observasi yang digunakan dalam penelitian ini adalah observasi terus terang. Peneliti menyatakan terus terang kepada sumber data, jika peneliti sedang melakukan penelitian. Jadi, mereka yang diteliti mengetahui dari awal sampai akhir tentang kegiatan peneliti. Namun, peneliti juga tidak berterus terang dalam suatu keadaan, ini untuk menghindari jika ada informasi yang sedang dicari adalah informasi yang masih dirahasikan dan jika dilakukan secara jujur, maka peneliti tidak akan diijinkan untuk melakukan observasi (Sugiyono, 2019, 299-300). Sedangkan dokumentasi yang dimaksud adalah buku ajar yang dimanfaatkan dalam pembelajaran PAI secara daring dan RPP guru. Teknik keabsahan data yang digunakan adalah triangulasi. Triangulasi diartikan kepada teknik pengumpulan data dan sumber data yang telah ada (Sugiyono, 2020, 125). Triangulasi yang digunakan dalam penelitian ini adalah triangulasi sumber dan triangulasi teknik. Triangulasi sumber, yaitu mengecek keabsahan data yang telah diperoleh darimsumber yang berbeda dengan teknik pengumpulan data yang sama. Sedangkan triangulasi teknik untuk mengecek keabsahan data yang didapat dari sumber yang sama dengan teknik pengumpulan data yang berbeda. Teknik analisis data yang peneliti gunakan terdapat empat tahapan yaitu Data Collection (Pengumpulan Data), Data Reduction (Reduksi Data), Data Display (Penyajian Data) dan Conclusion Drawing/Verification yang berpedoman pada analisis data versi Miles dan Humberman (Sugiyono, 2017, 133).

\section{Teknik Analisis Data}

Teknik analisis data yang peneliti gunakan terdapat empat tahapan yaitu Data Collection (Pengumpulan Data), Data Reduction (Reduksi Data), Data Display (Penyajian Data) dan Conclusion Drawing/Verification yang berpedoman kepada analisis data versi Miles dan Humberman (Sugiyono, 2017, 133).

\section{HASIL DAN PEMBAHASAN}

Strategi yang digunakan oleh guru PAI dalam mengembangkan kecerdasan spiritual siswa secara daring di SMAN 1 Pantai Lunci yaitu menggunakan strategi pembelajaran mandiri. Menurut Riza, dkk., pembelajaran mandiri adalah proses 
belajar yang dilakukan oleh peserta didik baik dalam lingkungan sekolah maupun di luar lingkungan sekolah dengan cara membaca, menelaah, serta memahami pengetahuan sesuai dengan materi pelajaran yang ada (Umam, 2020, 5). Adapun tahapan-tahapan dalam strategi pembelajaran mandiri menurut Sani dalam Iswangga (2020, 111) mencakup orientasi hingga tahap evaluasi sebagaimana dijelaskan sebagai berikut;

\section{Orientasi}

Untuk memperjelas arah yang ingin dicapai dalam suatu kegiatan pembelajaran maka seorang guru harus merumuskan sebuah tujuan pembelajaran yang akan dicapai. Tujuan pembelajaran yaitu tujuan yang ingin dicapai dalam proses pembelajaran melalui kegiatan yang direncanakan guru yang dimuat dalam sebuah RPP. Pada tahap ini guru PAI menentukan tujuan pembelajaran agar proses pembelajaran menjadi lebih terarah. Selain itu guru PAI juga menyampaikan tujuan pembelajaran kepada siswa agar siswa menjadi tahu tujuan yang akan capai dalam pembelajaran dilaksanakan.

\section{Penyajian}

Dalam sebuah pembelajaran penyajian penting sekali untuk dilakukan. Penyajian bisa dalam bentuk penyampaian materi pembelajaran dan tugas yang harus dipelajari oleh siswa. Penyampaian materi pembelajaran merupakan salah satu tugas pokok guru dalam kegiatan belajar mengajar guna mencapai tujuan pembelajaran yang telah ditetapkan. Penyampaian materi pembelajaran yang dilakukan oleh guru PAI secara daring adalah dengan membagikan file materi melalui google classroom, lalu memberikan tugas mandiri yang harus dikerjakan oleh siswa.

Tugas mandiri yang diberikan oleh guru PAI SMAN 1 Pantai Lunci antara lain merangkum materi dan membaca ayat al-Qur'an. Materi PAI yang dipelajari siswa berdasarkan temuan peneliti yang memiliki nilai spiritual yaitu materi bab 7 tentang "Malaikat Selalu Bersamaku". Nilai kecerdasan spiritual yang terkandung dalam materi "Malaikat Selalu Bersamaku" berdasarkan kurikulum 2013 adalah nilai akidah berupa menghayati nilai-nilai keimanan kepada malaikat-malaikat Allah SWT. Dengan adanya pemberian tugas mandiri untuk merangkum materi "Malaikat Selalu Bersamaku" secara tidak langsung siswa membaca materi yang telah ditugaskan sehingga sedikit banyaknya pengetahuan mereka dapat bertambah dan kecerdasan spiritual dapat berkembang pada sisi nilai akidah. 
Selain itu, pemberian tugas mandiri untuk membaca al-Qur'an merupakan salah satu cara yang dilakukan untuk mengembangkan kecerdasan spiritual pada sisi nilai ibadah karena membaca al-Qur'an termasuk dalam bentuk zikir sebagaimana yang telah disampaikan oleh Mamat dan Zarif $(2019,43)$ yang mengatakan bahwa solat dan membaca al-Qur'an merupakan sebaik-baik zikir. Pemberian tugas mandiri yang diberikan oleh guru PAI tersebut bertujuan untuk mengembangkan kecerdasan spiritual yang ada pada diri siswa.

Hal ini juga berkaitan dengan teori yang disampaikan oleh Zohar dan Marshall dalam Utami $(2015,168)$ yang mengemukakan bahwa salah satu jalan untuk mengembangkan kecerdasan spiritual di sekolah yaitu melalui pemberian tugas. Pemberian tugas ini dilakukan untuk memberikan ruang kepada siswa untuk melakukan kegiatannya sendiri. Hal ini akan melatih mereka memecahkan masalahnya sendiri. Guru tidak perlu khawatir murid akan melakukan kesalahan karena dalam setiap kegiatan belajar mengajar, anak dijelaskan manfaat mengapa anak perlu mempelajari hal tersebut sehingga dia sendiri memiliki motivasi untuk memperdalam materi tersebut. Jadi, antara strategi pembelajaran mandiri melalui tahapan ini bisa menjadi salah satu jalan untuk mengembangkan kecerdasan spiritual siswa.

\section{Kegiatan mandiri}

Kegiatan mandiri merupakan proses pemahaman materi pembelajaran yang dilakukan secara mandiri oleh siswa. Melalui materi pembelajaran dan tugas yang mereka pahami diharapkan dapat meningkatkan pengetahuan mereka terhadap Pendidikan Agama Islam sebagai jalan mereka untuk mengembangkan kecerdasan spiritual siswa. Hal ini berkaitan dengan teori yang disampaikan oleh Zohar dan Marshall dalam Utami $(2015,168)$ yang mengemukakan bahwa salah satu jalan untuk mengembangkan kecerdasan spiritual di sekolah yaitu melalui pengetahuan. Pengetahuan tersebut bisa didapat dari Pendidikan Agama Islam. Hal ini juga disampaikan oleh Majid dan Aswan dalam Akbar $(2019,42)$ yang mengatakan bahwa Pendidikan Agama Islam bertujuan untuk menumbuhkan dan meningkatkan keimanan melalui pemberian dan pemupukan pengetahuan. Melalui pengetahuan tentang Agama Islam peserta didik dapat menjadi manusia muslim yang terus berkembang dalam keimanan, ketakwaan berbangsa dan bernegara. Salah satu pengetahuan tentang Agama Islam yang dapat mengembangkan kecerdasan spiritual adalah materi tentang Malaikat Selalu Bersamaku. Nilai kecerdasan spiritual yang terkandung dalam materi 
Malaikat Selalu Bersamaku berdasarkan kurikulum 2013 adalah nilai akidah berupa menghayati nilai-nilai keimanan kepada malaikat-malaikat Allah SWT.

\section{Evaluasi}

Dari berbagai persoalan yang dihadapi dalam proses belajar mengajar evaluasi memberikan sumbangan yang cukup berarti. Evaluasi berfungsi sebagai acuan untuk memperbaiki kegiatan-kegiatan proses pembelajaran serta sebagai alat untuk menyeleksi dan sebagai alat untuk memberikan motivasi belajar siswa (Surawan dan Athailah, 2021, 89). Pada tahap ini selain mengetahui tingkat pemahaman siswa guru PAI juga melihat keaktifan mereka dalam mengumpulkan tugas secara tepat waktu. Sehingga, melalui pengumpulan tugas tersebut guru PAI bisa melihat tanggung jawab dan kedisiplinan siswa terhadap tugas-tugas yang telah diberikan. Selain itu, terkait hal yang berhubungan dengan kedisiplinan dalam mengumpulkan tugas secara tidak langsung, guru PAI juga mengajarkan mereka untuk menghargai waktu karena hal ini berkaitan dengan salah satu karakteristik seseorang yang memiliki spiritual yang tinggi. Menurut Hawari yang dikutip oleh Rosad (2020, 33) terkait hal tersebut, menumbuhkan sifat selalu menghargai waktu dan berlomba-lomba dalam hal kebenaran. Oleh sebab itu, melalui batasan waktu dalam pengumpulan tugas dapat menjadi salah satu cara untuk mengembangkan kecerdasan spiritual siswa, sehingga siswa menjadi lebih menghargai waktu.

\section{SIMPULAN DAN SARAN}

\section{Simpulan}

Strategi pembelajaran PAI yang digunakan oleh guru PAI dalam mengembangkan kecerdasan spiritual siswa secara daring di SMAN 1 Pantai Lunci adalah strategi pembelajaran mandiri dengan melalui beberapa tahapan yaitu menentukan tujuan pembelajaran, menyampaikan materi pembelajaran dan pemberian tugas mandiri berupa merangkum materi Malaikat Selalu Bersamaku yang di dalamnya mengandung nilai akidah dan membaca al-Qur'an yang didalamnya mengandung nilai ibadah, kemudian kegiatan mandiri (proses pemahamannmateri pembelajaran secara mandiri oleh siswa) dan tahapan yang terakhir yaitu dengan melakukan evalausi. 


\section{Saran}

Harapannya sebelum guru mengajarkan kepada siswa mengenai nilai-nilai kecerdasan spiritual, sebaiknya guru harus sudah mempraktikkan nilai-nilai spiritual tersebut di dalam kehidupan sehari-hari sehingga pada saat guru memberikan pengajaran mengenai nilai-nilai kecerdasan spiritual akan lebih mudah untuk diterima dan dipahami oleh siswa. Sedangkan bagi siswa dapat mengamalkan materi pembelajaran PAI yang telah dipelajari dalam kehidupan sehari-hari, lebih menjaga pergaulan dari pengaruh teman dan lingkungan yang kurang baik serta mematuhi aturan dan nasehat baik yang diberikan oleh guru PAI maupun orang tua agar menjadi pribadi yang berakhlakul karimah dimanapun berada.

\section{DAFTAR PUSTAKA}

Akbar, Doni. (2019). Pengaruh Rutinitas Membaca Al-Qur'an Sebelum Belajar Terhadap Prestasi Belajar Pendidikan Agama Islam di Kelas VIII SMP Negeri 19 Palembang. Jurnal Intelektualita: Kesilaman, Sosial, dan Sains. 8 (1).

Departemen Pendidikan Nasional. (2003). Undang-Undang RI Nomor 20 Tahun 2003 Tentang Sistem Pendidikan Nasional. Jakarta: CV Mitra Karya.

Dewi, Wahyu Aji Fatma. (2020). Dampak COVID-19 Terhadap Implementasi Pembelajaran Daring di Sekolah Dasar. Jurnal Ilmu Pendidikan. 2 (1).

Iswangga, Komara Dika, dkk., (2020). Strategi Pembelajaran Ekstrakurikuler Karawitan di SMA Negeri 1 Pemalang. Jurnal Seni Musik. 9 (2).

Kementerian Pendidikan dan Kebudayaan. (2020). Surat Edaran Nomor 4 Tahun 2020 Tentang Pelaksanaan Kebijakan Pendidikan dalam Masa Darurat Penyebaran COVID-19.

Mamat, Mohd Anuar dan Muhammad Mustaqim Mohd Zarif. (2019). Keperluan Zikir dalam Pembelajaran Menurut Manuskrip Melayu: Kajian Terhadap MSS 2906 (Tibyan Al-Maram). Journal of Al-Tamaddun. 14 (1).

Rosad, Wahyu Sabilar. (2020). Pelaksanaan Shalat Dhuha dalam Meningkatkan Kecerdasan Spiritual Siswa Kelas 3 Madrasah Ibtidaiyah Ma'arif Nu Ajibarang Wetan. Jurnal Ilmiah Mahasiswa Raushan Fikr. 9 (2).

Sugiyono. (2019). Metode Penelitian Kuantitatif, Kualitatif dan R\&D. Bandung: Alfabeta.

Surawan dan Muhammad Athailah. (2021). Ilmu Pendidikan Islam. Yogyakarta: KMedia 
52 | Komariah, Hamdanah, \& Surawan

Umam, Syaiqul. (2020). Pemilihan Strategi Sebagai Alternatif Solusi Permasalahan Pembelajaran Berbasis Daring. Journal Of Education. 1(1).

Utami, Lufiana Harnany. (2015). Pengembangan Kecerdasan Spiritual Siswa di SD Islam Tompokersan Lumajang. Jurnal Ilmiah Psikologi. 2 (1), 63-78. 